\title{
IMPLEMENTASI PENDIDIKAN KEWIRAUSAHAAN SEBAGAI CHARACTER BUILDING MAHASISWA PENDIDIKAN EKONOMI UNPGRI KEDIRI
}

\author{
Zainal Arifin ${ }^{1)}$, Efa Wahyu Prastyaningtyas ${ }^{2)}$ \\ Universitas Nusantara PGRI Kediri ${ }^{1)}$, Universitas Nusantara PGRI Kediri ${ }^{2}$ \\ zainalarifin@unpkediri.ac.id ${ }^{1)}$, efawahyu@unpkediri.ac.id ${ }^{2)}$
}

\begin{abstract}
Entrepreneurship is a course that aims to provide understanding and skills to students about entrepreneurs, in accordance with the learning objectives of being able to understand, analyze basic concepts of entrepreneurship and business ethics, create and use a trusted and effective business plan. This study aims to determine whether the implementation of entrepreneurship education affects the character building of UN PGRI Kediri economic education students in the practice of entrepreneurship, by looking at before and after getting $K W U$ education whether it can generate character buliding for students. This study is classified as an experimental study using the Wilcoxon signed rank test design with one group pre test post test design. This study shows a positive result that entrepreneurship education has a significant effect on student character building.
\end{abstract}

Keywords: Entrepreneurship education, Character Building

\begin{abstract}
Abstrak
Kewirausahan merupakan mata kuliah yang bertujuan untuk memberikan pemahaman dan skill kepada mahasiswa tetang berwirausaha, sesuai dengan tujuan pembelajaran yaitu mampu memahami, menganalisis konsep dasar kewirausahaan dan etika bisnis, membuat serta menggunakan rencana usaha yang terpercaya dan efektif. Penelitian ini bertujuan untuk mengetahui apakah implementasi pendidikan kewirausahaan berpengaruh terhadap character building mahasiswa pendidikan ekonomi UNPGRI Kediri dalam praktek berwirausaha, dengan melihat sebelum dan sesudah mendapatkan pendidikan KWU apakah bisa membangkitkan character buliding bagi mahasiswa. Penelitian ini tergolong penelitian eksperimen menggunakan desain wilcoxon signed rank test dengan model one group pre test post test design. Penelitian ini menunjukkan hasil positif bahwa pendidikan kewirausahaan berpengaruh signifikan terhadap character building mahasiswa.
\end{abstract}

Kata Kunci: Pendidikan Kewirausahaan, Character Building 


\section{PENDAHULUAN}

Kemenristek Dikti pada tahun 2018 mencatat sekitar $8,8 \%$ dari total 7 juta pengangguran di Indonesia adalah sarjana. Kondisi tersebut sangat mengkhawatirkan mengingat persaingan untuk mendapatkan pekerjaan akan semakin ketat dengan datangnya Revolusi industri 4.0 (www.pikiranrakyat.com/pendidikan/2018/0 3/26). Selain persaingan dengan mesin berbasis teknologi canggih, sekitar 630.000 sarjana pengangguran tersebut juga harus beradu kompetensi dan keahlihan tertentu dengan pekerja asing yang datang dari terbukanya pasar bebas. Perguruan tinggi sebagai lembaga pencetak sumber daya manusia yang unggul diharapkan dapat memberikan kontribusi besar terhadap upaya peningkatan kapasitas sumberdaya manusia. Kesulitannya sarjana menembus dunia kerja karena relevansi antara mutu perguruan tinggi dan kebutuhan dunia industri masih rendah.

Salah satu tugas penting sistem dan lembaga pendidikan kita saat ini adalah mengembalikan pendidikan pada fungsinya sebagai wahana pembangunan karakter bangsa (character building). Maka, lembaga pendidikan tidak hanya bertugas memindahkan ilmu dan teknologi kepada generasimuda, tetapi juga internalisasi nilainilai luhur dan ideal bagi kehidupan antar generasi. Jika transfer ilmu hanya menyentuh aspek kognitif dan penguasaan kecakapan hidup dan teknologi merupakan kompetensi pada ranah kognitif dan psikomotorik, maka internalisasi nilai-nilai luhur kehidupan yang menjadi inti dari pembentukan karakter bangsa merupakan kompetensi peserta didik lebih menekankan pada ranah afektif, di samping kognitif dan psikomotorik.

Jiwa kewirausahaan mempunyai ciriciri yang sesuai dengan budaya dan karakter bangsa yang pada saat ini mendapat perhatian serius dunia pendidikan. Melalui mata kuliah kewirausahaan akan dapat dikembangkan budaya dan karakter; tanggung jawab, kerja keras, keuletan dan ketekunan, kreatif dan inovatif, disiplin, jujur, dan peduli sosial (Sudarmiani, 2014). Perguruan tinggi merupakan institusi pendidikan yang diharapkan dapat menghasilkan lulusan dengan kemampuan akademis pada bidang keilmuan yang ditekuni.Selain itu perguruan tinggi merupakan agent of change yang mempersiapkan mahasiswa menjadi pribadi unggul, tangguh, dan kompeten dalam terjun bermasyarakat. Salah satu yang dilakukan melalui pengembangan pendidikan enterpreneur (Prastyaningtyas, 2016).

Keluarnya sejumlah peraturan perundang-undangan seperti UU No. 12 tahun 2012 tentang pendidikan tinggi, Perpres No. 8 tahun 2012 tentang kerangka kualifikasi nasional Indonesia (KKNI), dan Permendikbud No. 49 tahun 2014 tentang standar nasional pendidikan tinggi, memberikan pesan kuat bahwa pendidikan tinggi harus mampu melahirkan manusia Indonesia yang cakap, berkarakter, dan berdaya saing. Pendidikan tinggi berfungsi mengembangkan kemampuan dan membentuk watak serta peradaban bangsa yang bermartabat dalam rangka mencerdaskan kehidupan bangsa (Kemdikbud, 2012a). Selain itu, pendidikan tinggi harus mampu memberdayakan mahasiswa menjadi manusia terdidik (educated person) yang berpengetahuan, kreatif, inovatif, dan berkarakter. Manusia Indonesia juga harus mampu sejajar dan bersaing dengan warga bangsa yang lain. Kualifikasi manusia Indonesia seperti itulah yang diharapkan bisa terbentuk melalui proses pendidikan di perguruan tinggi. Hal ini sejalan dengan hasil penelitian terkait dengan keterampilan yang dibutuhkan diabad 21. Ada lima keterampilan pokok yang perlu dimiliki, yakni keterampilan beradaptasi, berkomunikasi kompleks, memecahkan masalah nonrutin, manajemen diri, dan berpikir sistem (National Academy of Sciences, 2011).

Chimucheka (2013), menyatakan bahwa salah satu faktor pendorong pertumbuhan kewirausahaan di suatu negara terletak pada peranan universitas melalui penyelenggaraan pendidikan kewirausahaan. Kewirausahaan muncul apabila seseorang individu berani mengembangkan usaha- 
usaha dan ide-ide barunya.Pendidikan kewirausahaan adalah aktivitas-aktivitas pengajaran dan pembelajaran tentang kewirausahaan yang meliputi pengembangan pengetahuan, ketrampilan, sikap dan karakter pribadi sesuai dengan umur dan perkembangan siswa (Isrososiawan, 2013).

Hasil penelitian sebelumnya yang mengkaji pendidikan kewirausahaan menyatakan bahwa mahasiswa yang berpengalaman mengembangkan berbagai ketrampilan teknis dan pelatihan lebih percaya diri menjadi wirausaha (Chen et el, 2010). Sikap kewirausahaan adalah agen perubahan yang berpengaruh terhadap produktivitas dan profitabilitas (Borasi dan Finnigan, 2010).

Karakter menurut Zubaidi (2011) yaitu suatu penilaian subjektif terhadap kepribadian seseorang yang berkaitan dengan atribut kepribadian yang dapat atau tidak dapat diterima masyarakat. Zainal dan Sujak (2011) menyatakan karakter mengacu pada serangkaian sikap (attitude), perilaku (behaviors), motivasi (motivation) dan ketrampilan (skills). Menurut Kementrian Pendidikan Nasional (2010) karakter adalah watak, tabiat, akhlak atau kepribadian seseorang yang terbentuk dari hasil internalisasi berbagai kebajikan (virtues) yang diyakini dan digunakan sebagai landasan untuk cara pandang berpikir, bersikap dan bertindak.
Suyanto, (2010) menyatakan bahwa terdapat sembilan pilar karakter yang berasal dari nilai-nilai luhur universal, yaitu (1) karakter cinta Tuhan dan segenap ciptaan Nya; (2) kemandirian dan tanggungjawab; (3) kejujuran/amanah, diplomatis; (4) hormat dan santun; (5) dermawan, suka tolong-menolong dan gotong royong/kerjasama; (6) percaya diri dan pekerja keras; (7) kepemimpinan dan keadilan; (8) baik dan rendah hati, dan (9) karakter toleransi, kedamaian, dan kesatuan.

Mendasarkan pada pilar pendidikan karakter baik yang dikemukakan olehpara penggiat pendidikan karakter maupun oleh Suyanto dan ciri-ciri danwatak wirausaha yang sukses sebagaimana disebutkan di atas menunjukkan bahwa pendidikan karakter sangat menunjang terhadapsemangat kewirausahaan. Pilar-pilar dalam pe ndidikan karakter yang harusdilaksanakan sangat sejalan dengan ciri-ciri dan watak wirausaha yang sukses. Pilar-pilar pendidikan karakter sebagaimana dikemukakan di atas sangat identik dan satu jiwa dengan ciri danwatak wirausaha yang sukses. Beberapa pilar pendidikan karakter dan ciri-ciri atau watak wirausaha yang sukses secara ringkas dapat ditunjukkan pada Tabel 1.

\section{Tabel 1}

Beberapa ciri atau karakter yang dapat dipadankan antarapendidikan karakter dan watak wirausaha

Perubahan kurikulum Prodi Pendidikan Ekonomi Universitas Nusantara PGRI Kediri Pilar Pendidikan karakter Ciri dan Watak Wirausaha
1) Tanggung jawab (responsibility)
1) Percaya diri
2) Rasa hormat (respect)
2) Berorientasi tugas dan hasil
3) Keadilan (fairness)
3) Pengambil resiko
4) Keberanian (coiurage)
4) Kepemimpinan
5) Kejujuran (honesty)
5) Keorisinilan
6) Kewarganegaraan (citizenship)
6) Berorientasi ke masa depan
7) Disiplin diri (self-dicipline)
7) Jujur dan tekun
8) Peduli (caring)
8) Bertanggungjawab
9) Ketekunan (perseverance)
9) Inisiatif dan proaktif 
menjadi berbasis KKNI yang baru berjalan 2 tahun membawa dampak terhadap sebaran mata kuliah yang ada, terutama pada mata kuliah kewirausahaan tidak hanya 2 sks melainkan menjadi 2 sks kwu dan 2 sks praktik kwu. Sebagai dosen pengampu mata kuliah maka berkewajiban untuk menanamkan karakter-karakter yang harus dimiliki seorang enterpreneur pada mahasiswa melalui program perkulihan yang ada. Oleh karena itu karakter kewirausahaan diantara mahasiswa harus dibangkitkan agar jumlah wirausaha terdidik dari kalangan perguruan tinggi meningkat dan jumlah pengangguran berkurang. Untuk mewujudkan itu maka mahasiswa Pendidikan Ekonomi UN PGRI Kediri perlu diberikan pendidikan kewirausahaan, supaya terbentuk character buildingkhususnya dalam praktek berwirausaha.

Berdasarkan latar belakang di atas rumusan masalah pada penelitian ini yaitu apakah implementasi pendidikan kewirausahaan berpengaruh terhadap character building mahasiswa pendidikan ekonomi UNP Kediri dalam praktek berwirausaha?

\section{METODE PENELITIAN}

Metode penelitian yang digunakan dalam penelitian ini adalah metode eksperimen. Penelitian ini menggunakan Quasi Eksperimen yaitu penelitian yang menggunakan percobaan yang sesungguhnya dimana tidak mungkin menggunakan kelas kontrol atau manipulasi dari semua variabel yang relevan. Perlu adanya kompromi dalam menentukan validitas internal dan eksternal sesuai dengan batas-batas yang ada (Nazir, 2011).Desain penelitian eksperimennya adalah One-Group-Pretest-Postest, dengan tidak menggunakan kelas kontrol.Desain penelitian ini sebagai berikut:

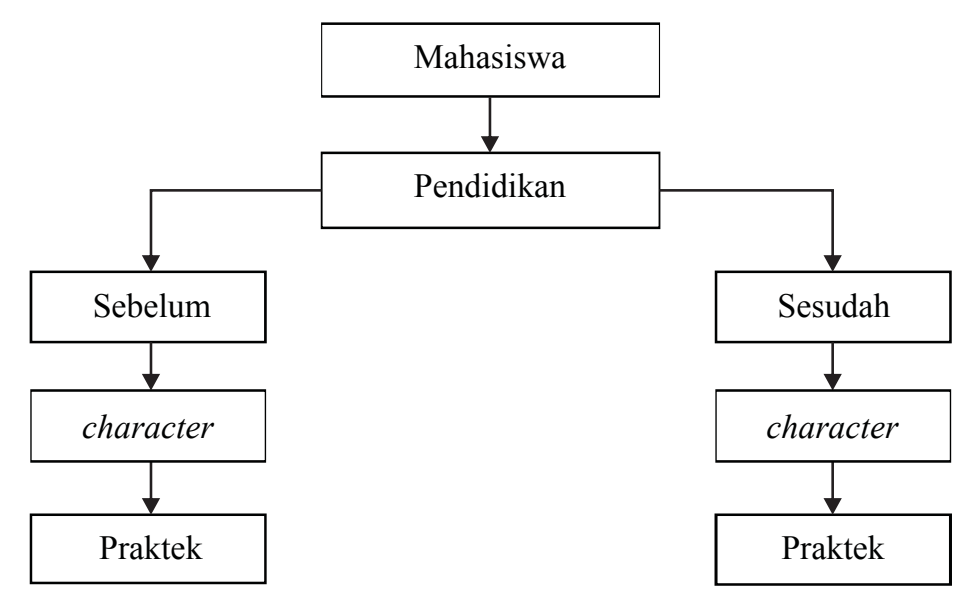

Populasi penelitian ini adalah seluruh mahasiswa Pendidikan Ekonomi UNPGRI Kediri. Sampel penelitiannya adalah mahasiswa Pendidikan Ekonomi yang menempuh mata kuliah kewirausahaan yang berjumlah 12 mahasiswa. Teknik pengambilan Sampel penelitian ini menggunakan teknik purposive Sampling".

Pengumpulan data dilakukan dengan metode wawancara dan melalui pre test post tes. Analisis data yang digunakan adalah uji beda wilcoxon. Menurut Sujarweni (2016)
Uji wilcoxon digunakan untuk menentukan ada tidaknya perbedaan rata-rata dua sampel yang saling berhubungan. Jika data sampel bertipe interval atau rasio, serta distribusi data mengikuti distribusi normal, bisa dilakukan uji parametrik untuk dua sampel berhubungan, seperti uji t paired. namun jika salah satu syarat tersebut tidak terpenuhi yaitu data bertipe nominal atau ordinal, data bertipe interval atau rasio, namun tidak berdistribusi normal. Maka uji t paired harus diganti dengan uji non parametrik yang khusus 
digunakan untuk dua sampel yang saling berhubungan.

Hipotesis penelitian ini yaitu:

$\mathrm{H}_{0}=$ tidak ada pengaruh implementasi pendidikan kewirausahaan terhadap character building mahasiswa pendidikan ekonomi UNPGRI Kediri dalam praktek berwirausaha

$\mathrm{H}_{1}$ = ada pengaruh implementasi pendidikan kewirausahaan terhadap character building mahasiswa pendidikan ekonomi UNPGRI Kediri dalam praktek berwirausaha

Untuk membantu memudahkan dalam analisis data digunakan bantuan program IBM SPSS statistik 24.

\section{HASIL DAN PEMBAHASAN}

Mata kuliah praktek kewirausahaan program studi pendidikan ekonomi diberikan pada mahasiswa tingkat II dengan capain pembelajarannya yaitu meningkatkan kemampuan dan memberikan pengalaman berwirausaha bagi mahasiswa dengan meningkatkan ketrampilan dan perilaku wirausaha mahasiswa melalui penemuan dan presentasi ide, kreatifitas dan inovasi berwirausaha, pelaksanaan dan pengendalian berwirausaha, serta monitoring dan tindak lanjut dalam berwirausaha. Satuan acara perkuliahan praktek kwu sebagai berikut:

Tabel 2: SAP Praktek KWU

\begin{tabular}{cll} 
Pertemuan & \multicolumn{1}{c}{ Materi } & Metode \\
\hline 1 & $\begin{array}{l}\text { SAP \& Aturan } \\
\text { Perkuliahan }\end{array}$ & Ceramah \\
& $\begin{array}{l}\text { Kreativitas dan } \\
\text { Inovasi untuk } \\
\text { Menemukan Ide }\end{array}$ & \\
& Ceramah \\
& Bisnis & \\
& Mekanisme \& & Ceramah \\
& Rancanagan Bisnis & \\
& (Bussnis Plan) & \\
& Survey Unit Bisnis & Survey \\
& $\begin{array}{l}\text { yang sesuai dengan } \\
\text { ide bisnis di }\end{array}$ & lapangan \\
& UMKM & \\
& Studi Kelayakan & Studi \\
& Bisnis dan & Kelayakan \\
& Penyusunan & Bisnis \\
& Rancangan Bisnis & \\
& (Business Plan) &
\end{tabular}

\begin{tabular}{|c|c|c|}
\hline \multirow[t]{2}{*}{6} & Presentasi Business & Presentasi \\
\hline & Plan Kelompok 1\&2 & kelompok \\
\hline \multirow[t]{2}{*}{7} & Presentasi Business & Presentasi \\
\hline & Plan Kelompok 3\&4 & kelompok \\
\hline \multirow[t]{2}{*}{8} & Presentasi Business & Presentasi \\
\hline & Plan Kelompok 5\&6 & kelompok \\
\hline \multirow[t]{2}{*}{9} & UTS $=$ Proposal & Pengumpulan \\
\hline & $\begin{array}{l}\text { Rancangan Bisnis } \\
\text { (Business Plan) }\end{array}$ & Laporan \\
\hline \multirow[t]{2}{*}{10} & $\begin{array}{l}\text { Pelaksanaan usaha } \\
\text { oleh mahasiswa }\end{array}$ & $\begin{array}{l}\text { Praktek, } \\
\text { Presentasi }\end{array}$ \\
\hline & $\begin{array}{l}\text { Monitoring dan } \\
\text { evaluasi Dosen }\end{array}$ & hasil praktek \\
\hline \multirow[t]{2}{*}{11} & $\begin{array}{l}\text { Pelaksanaan usaha } \\
\text { oleh mahasiswa }\end{array}$ & $\begin{array}{l}\text { Praktek, } \\
\text { Presentasi }\end{array}$ \\
\hline & $\begin{array}{l}\text { Monitoring dan } \\
\text { evaluasi Dosen }\end{array}$ & hasil praktek \\
\hline \multirow[t]{2}{*}{12} & $\begin{array}{l}\text { Pelaksanaan usaha } \\
\text { oleh mahasiswa }\end{array}$ & $\begin{array}{l}\text { Praktek, } \\
\text { Presentasi }\end{array}$ \\
\hline & $\begin{array}{l}\text { Monitoring dan } \\
\text { evaluasi Dosen }\end{array}$ & hasil praktek \\
\hline \multirow[t]{2}{*}{13} & $\begin{array}{l}\text { Pelaksanaan usaha } \\
\text { oleh mahasiswa }\end{array}$ & $\begin{array}{l}\text { Praktek, } \\
\text { Presentasi }\end{array}$ \\
\hline & $\begin{array}{l}\text { Monitoring dan } \\
\text { evaluasi Dosen }\end{array}$ & hasil praktek \\
\hline \multirow[t]{2}{*}{14} & $\begin{array}{l}\text { Pelaksanaan usaha } \\
\text { oleh mahasiswa }\end{array}$ & $\begin{array}{l}\text { Praktek, } \\
\text { Presentasi }\end{array}$ \\
\hline & $\begin{array}{l}\text { Monitoring dan } \\
\text { evaluasi Dosen }\end{array}$ & hasil praktek \\
\hline \multirow[t]{2}{*}{15} & Entrepreneurship & Bazar \\
\hline & Day Competition & \\
\hline \multirow[t]{4}{*}{16} & UAS (Pembuatan & \\
\hline & Laporan Akhir & \\
\hline & Praktikum & \\
\hline & Kewirausahaan) & \\
\hline
\end{tabular}

Melalui mata kuliah kewirausahaan akan dapat dikembangkan budaya dan karakter; tanggung jawab, kerja keras, keuletan dan ketekunan, kreatif dan inovatif, disiplin, jujur, dan peduli sosial.

\section{Hasil analisis data dengan menggunakan uji Wilcoxon didapatkan hasil sebagai berikut:}

Tabel 3

Uji pengaruh hasil pretest dan postes

\begin{tabular}{lr}
\hline \multicolumn{2}{c}{ Test Statistics $^{a}$} \\
\hline & postest-pretest $^{b}$ \\
$Z$ & $-3,07 I^{b}$ \\
Asymp. Sig. (2-tailed) &, 002 \\
\hline
\end{tabular}


Dilihat dari tabel 3 di atas menunjukkan bahwa nilai sig sebesar 0,002 yang artinya kurang dari nilai $\alpha$ yang telah ditetapkan yaitu sebesar 0,05. Dengan demikian dapat diartikan bahwa implementasi pendidikan kewirausahaan memberikan pengaruh yang signifikan terhadap character building mahasiswa pendidikan ekonomi UNPGRI Kediri dalam praktek berwirausaha.

Tabel 4

Peningkatan hasil pretes postes mahasiswa

\begin{tabular}{|l|l|r|r|r|}
\hline \multicolumn{5}{|c|}{ Ranks } \\
\hline \multicolumn{2}{|c|}{$N$} & $\begin{array}{c}\text { Mean } \\
\text { Rank }\end{array}$ & $\begin{array}{c}\text { Sum of } \\
\text { Ranks }\end{array}$ \\
\hline $\begin{array}{l}\text { postest - } \\
\text { pretest }\end{array}$ & $\begin{array}{l}\text { Negative } \\
\text { Ranks }\end{array}$ & $0^{\mathrm{a}}$ &, 00 &, 00 \\
\cline { 2 - 6 } & $\begin{array}{l}\text { Positive } \\
\text { Ranks }\end{array}$ & $12^{\mathrm{b}}$ & 6,50 & 78,00 \\
\cline { 2 - 5 } & Ties & $0^{\mathrm{c}}$ & & \\
\cline { 2 - 6 } & Total & 12 & & \\
\hline
\end{tabular}

(a). postest $<$ pretest (b). postest $>$ pretest (c). postest $=$ pretest

Pada tabel 4 diketahui bahwa nilai postes mengalami peningkatan lebih baik dari pretes. Hal ini ditunjukkan pada hasil positive ranks bahwa ke 12 mahasiswa mengalami peningkatan yang signifikan.

Tabel 5

Rata-rata hasil pretest dan postes

\begin{tabular}{lccrrr}
\multicolumn{7}{c}{ Descriptive Statistics } \\
& N & Mean & Deviation & Minimum & Maximum \\
\hline pretest & 12 & 70,08 & 8,163 & 53 & 79 \\
postest & 12 & 78,58 & 5,518 & 69 & 90 \\
\hline
\end{tabular}

Berdasarkan pada tabel 5 rata-rata nila pretest sebesar 70,08 sedangkan nilai postes sebesar 78,58 . Hal ini menunjukkan bahwa rata-rata nilai postes lebih tinggi dari pada nilai pretes. Artinya pengaruh yang diberikan dari implementasi pendidikan kewirausahaan terhadap character building mahasiswa pendidikan ekonomi UNPGRI Kediri dalam praktek berwirausaha merupakan pengaruh yang positif.

\section{PENUTUP}

\section{Simpulan}

1. Pendidikan kewirausahaan membawa dampak positif terhadap character building mahasiswa.

2. Ada perbedaan pengaruh implementasi pendidikan kewirausahaan terhadap character building pada mahasiswa Pendidikan Ekonomi UN PGRI Kediri, sebelum mendapat pendidikan KWU character building mahasiswa rendah diikuti dengan praktek wirausaha yang rendah pula. Sedangkan setelah mendapat pendidikan KWU character building naik diikuti dengan praktek KWU yang juga meningkat.

\section{Saran}

1. Pendidikan kewirausahaan harus ditanamkan sejak usia dini agar mampu membangun karakter seseorang yang lebih maju dan inovatif.

2. Penelitian selanjutnya diharapkan lebih dalam lagi dalam mengkaji kewirausahaan sebagaicharacter building mulai dari pendidikan menengah.

3. Berbagai macam factor yang mempengaruhi character building diharapkan dapat diteliti lebih lanjut untuk menentukan langkah bagaimana menciptakan character building.

\section{DAFTAR PUSTAKA}

Borasi, R., \& Finnigan, K. (2010). Entrepreneurial attitudes and behaviors that can help prepare successful change-agents in education. The New Educator, 6(1), 129.

Chen, W. Y., Weng, C. S., \& Hsu, H. Y. (2010). A study of the entrepreneurship of Taiwanese youth by the Chinese Entrepreneur Aptitude Scale. Journal of Technology Management in China, 5(1), 26-39.

Chimucheka, Tendai. (2013). The Impact of Entrepreneurship Education on the Establishment and Survival of 
Small, Micro and Medium Enterprises (SMMEs). Journal Economics, 4(2): 157-168.

Isrososiawan, S. (2013). Peran Kewirausahaan dalam Pendidikan. Society, 9(1), 26-49

Kemdikbud (2012). Undang-undang nomor 12 tahun 2012 tentang pendidikan tinggi. Jakarta: Kemdikbud

Kementerian Pendidikan Nasional. (2010). Konsep Dasar Kewirausahaan. Jakarta: Direktorat Jenderal Pendidikan Informal dan Nonformal.

National Academy of Sciences (2011). Assessing 21st Century Skills: Summary of a Workshop. Washington: Division of Behavioral and Social Sciences and Education

Nazir. Metode Penelitian. (2011). Jakarta: Ghalia Indonesia.

Peraturan Pemerintah Nomor 20 Tahun 2003 tentang Sistem Pendidikan Nasional

Prastyaningtyas, Efa Wahyu. (2016). Pendidikan Enterprneur Pada
Perguruan Tinggi sebagai Salah Satu Pondasi dalam Menghadapi MEA ( Masyarakat Ekonomi ASEAN)Prosideng SEMNAS 2016 S T K I P T u $1 \mathrm{u} \mathrm{n} \mathrm{g}$ a $\mathrm{g} \mathrm{un} \mathrm{g}$. https://drive.google.com/file/d/0BwiS1ls U3F9NSkpPWDFzRVhHNEE/view

Sudarmiani. (2014). Pengembangan nilainilai karakter mahasiswa melalui mata kuliah kewirausahaan. Prosideng Seminar Nasional Pendidikan dalam Rangka Dies Natalis ke 37 Universitas Sebelas Maret.http://jurnal.fkip.uns.ac.id/ind ex.php/psdtp/article/view/3677/2578

Sujarweni, Wiratna. (2016). Penelitian Akuntansi dengan SPSS. Yogyakarta: Pustaka Baru Press

Zainal, A \& Sujak. (2011). Panduan dan Aplikasi Pendidikan Karakter. Jakarta: Gaung Persada Press.

Zubaidi. (2011). Desain Pendidikan Karakter: Konsepsi dan Aplikasinya dalam Lembaga Pendidikan. Jakarta: Kencana 